\title{
EFFECT OF CYLINDRICAL PIN DEPTH ON THE TEMPERATURE DISTRIBUTION OF DISSIMILAR FRICTION STIR SPOT WELDING (FSSW)
}

\author{
Kayser Aziz Ameen \\ kayser@esraa.edu.iq \\ Al-Esra'a University College, Baghdad-Iraq
}

\begin{abstract}
Friction stir spot welding (FSSW) is provided a premium difference to resistance spot welding and rivet process for making the structures of aluminum sheet and it is a new development. ANSYS works is done which conducted on dissimilar material sheets of a1.1 mm thick sheet of aluminum alloy (AA2024-T3) and a $0.8 \mathrm{~mm}$ thick sheet of carbon steel (1006-AISI). A 3-D finite element model was built using ANSYS APDL to simulate the thermal and mechanical model during FSSW. The welding processes are performed using cylindrical pin with a $10 \mathrm{~mm}$ diameter. Three tool rotational speeds are used during FSSW processes (900rpm, 1400rpm, 1800rpm). Results showed that the maximum temperature was $242.57^{\circ} \mathrm{C}$ in nugget zone of dissimilar spot weld, at $15 \mathrm{sec}$ with a $0.4 \mathrm{~mm}$ depth and $135.752^{\circ} \mathrm{C}$ at $10 \mathrm{sec}$ with a depth of $0.2 \mathrm{~mm}$.
\end{abstract}

KEYWORDS: Friction stir spot welding, AA2024, Dissimilar friction stir spot welding, carbon steel, ANSYS, finite element method.

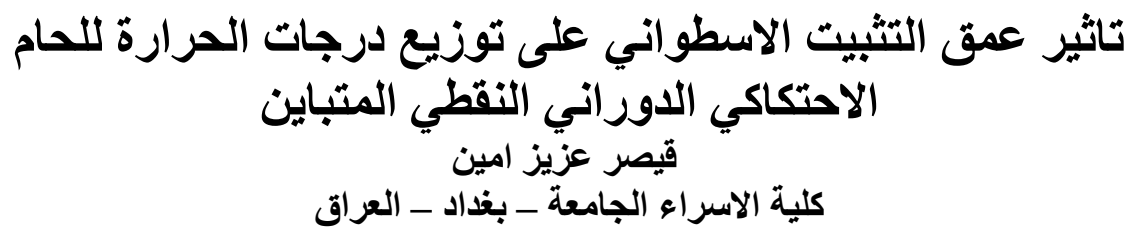

الخلاصة

اللحام الاحتكاكي الدوراني النقطي اعطى دفعة تشجيعية تختلف في المقاومة عن اللحام النقطي و استعمال البراشيم

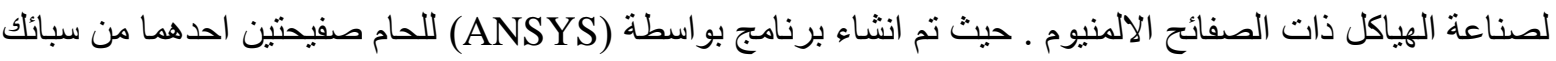

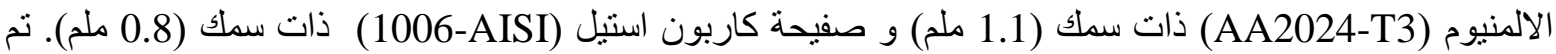

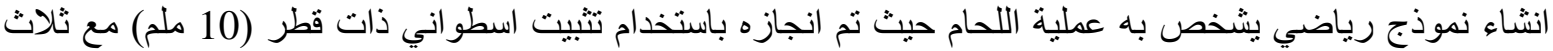

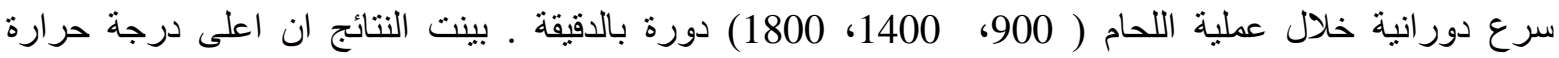

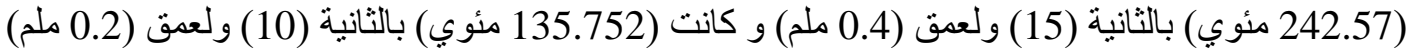




\section{INTRODUCTION}

Since its implement in 2003, friction stir spot welding showed a major point to be in state of single point welding process, as riveting and resistance spot welding, and it had been many applications in aviation, aerospace, and the field of automobile. The strength of FSSW is affected by the welding parameters, such as rotational speed, plunging depth, dwell time and plunging rate. On the other hand, the welding process is one of the manufacturing processes that cause residual stresses to remain in the finished products. Generally, residual stresses can be beneficial or harmful depending on its behavior, i.e. compressive or tensile. In FSSW, the joining is similar around the hole of pin, sothe microstructure on one side of the product hole observes as a reflected photo to that on the other side, the zone of the exists width, that the lower and upper sheets are completely bonded. The width of this zone is called "bond width". The completely bonded ends on the external boundary among a stir region and thermo mechanical heat affected zone. After that the partial bonded zone appeared, that the lower and upper sheets are disconnected by discontinuous interface line. The partial bonded zone is generally consisted inclusively with the radius of the shoulder. On the starting of the partially bonded zone, since stirring and plunging action of the tool, the interface line disconnecting the lower and upper sheets turns upward a lite part, thus, a "hook" region is forming [1], as shown in Figure (1). Figner et al.,2009, examined friction stir spot welded forHX340 LA Dsteel sheets with thickness $1 \mathrm{~mm}$, and AA5754-H111 with thickness $2 \mathrm{~mm}$. The selection of the speed of spindle and dwell time are illustrated which the spot-welding strength could be significant improved. Hence, a max. load is $8.4 \mathrm{kN}$ per spot in the shear tension test but when the dwell time increasing, the intermetallic phases (IMP) value will be increased and break off, caused to decrease the strength. Bozzi et al., 2010, examined the holding of AA6016 with thickness $1 \mathrm{~mm}$ and $2 \mathrm{~mm}$ to galvanized steel sheet (kind IF) with $2 \mathrm{~mm}$ thickness using an instrument machined in tungsten rhenium composite (W25Re). The outcomes demonstrated that expanded the intermetallic mixes layer thicknesses, caused to raise the rotational speed and the depth of penetrated alloy. Additionally, outlined that the intermetallic mixes disclose to be basic to build up the weld quality, either the compound layer of intermetallic is thick crack start and propagated effortlessly amid the weak intermetallic mixes layer. Chen et al., 2012,1 mm thick 6111-T4 Al and DC04 low carbon steel sheet is welded. The apparatus had a $11 \mathrm{~mm}$ distance across steel bear, with a parchment profile to enhance the stream of material, and a decreased $3 \mathrm{~mm}$ dia. WC $1 \mathrm{~mm}$ long test. The range of the tests orbital way was $2.5 \mathrm{~mm}$ that created a cleared zone of $8 \mathrm{~mm}$ dia. on the surface of steel. They delivered top spot welds between thin $\mathrm{Al}$ and steel car sheet inside a weld time of $1 \mathrm{sec}$ that is a coveted target time by industries. Sun et al., 2013, studied the geometry of bear toolhavingconcave-shapedwith12

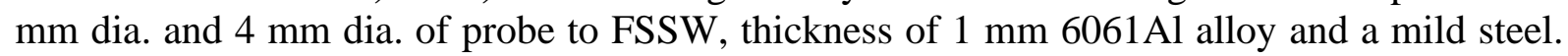
Watched non intermetallic compound (IMC) layer along the $\mathrm{Al} / \mathrm{Fe}$ interface in the wake of welding delivered. Also showed the shear tensile damage loadsarereachedof $3607 \mathrm{~N}$ as a maximum value. A little influence for pin length on the specification of welding, that illustrates the life of tool could be extended by FSSW spot welding technique.D.KLOBCAR, et al., 2014, contemplated the parameters contact with friction stir spot welding (FSSW) of aluminum compound AA5754 into the lap joint. Test work is finished showing to the consequences of surface technique that rotational device speed changed somewhere in the range of $988 \mathrm{rpm}$ and $3511 \mathrm{rpm}$, rate of dive between $24.4 \mathrm{~mm} / \mathrm{min}$ and $150 \mathrm{~mm} / \mathrm{min}$ and stay time somewhere in the range of $1 \mathrm{~s}$ and $3.5 \mathrm{~s}$. The profundity of dive is steady at $0.4 \mathrm{~mm}$. The welds were pliable shear tried and the microstructure was breaking down. Numerical models were produced to outlined the connection between welding parameters and spot quality, axial force and rotational torque and the streamlining of the parameters of FSSW was considered. 
Mukuna P. Mubiayi et al., 2014, observed the reviewing of FSSW of similar and dissimilar metals and illustrated to fill the holes to grow FSSW mechanically. The checking on of FSSW are abridged regarding the developing microstructure and mechanical properties between aluminum composites and different materials like copper, steel and magnesium. Friction stir spot welding is achieved through Muna K.Abbass et al., 2015 ,with varied of rotational tool velocity(800,1000and $1250 \mathrm{rpm})$, plunging times of $(30,60$ and $90 \mathrm{sec})$ with profile of pin device (Threaded tube with flute, Tapered and straight cylindrical). Optimization of the parameters were done using Taguchi method and with relate to the design of experiment (DOE). The aluminum sheet was overlapped on the copper sheet. The results showed that the max. shear force is $(1527 \mathrm{~N})$ found in optimum parameters of welding with $1250 \mathrm{rpm}$ rotation speed and $90 \mathrm{sec}$ diving time and straight round and hollow stick profile, that are get from the examining of the reaction analyzer. Pareto outline is utilized for institutionalizing impacts of ductile shear comes about clarifies that the diving time was the extremely affected parameter between the other welding parameters. The temperature distribution measured in three locations that the nugget zone of the spot weld, the base aluminum alloy(AA2024T3) and base pure copper, results showed that the max. measured temperature was $383 \mathrm{C}$. in the nugget zone of the weld. A few researches are available about the friction stir spot welding of dis-similar material sheets of aluminum alloy AA2024-T3 and sheet of carbon steel (1006-AISI). The aim of this work is to examine the temperature and stress distribution due to the friction stir spot welding of these dis-similar material.

\section{FRICTION STIR SPOT WELDING (FSSW) TECHNIQUE}

The device used in FSSW process is similar to that of Timothy J M (2008). The bulk of the friction or heat for deformation is generated by the shoulder while the pin helps a metal for flow with workpieces. In addition to the tool, other parameters in FSSW are, the rotation tool speed; plunge depth of tool and the stayed time. The parameters of welded joints evaluated a strength and the finishing of the surface. In this study two types of materials are used; (AA2024-T3) Aluminum alloy and(1006-AISI) carbon steel. A sheet of $1.1 \mathrm{~mm}$ thickness of Aluminum alloy AA2024-T3 and 0.8mm of carbon steel (1006-AISI) is used. The welded specimens were consisting of two sheets $(100 \mathrm{~mm} \times 25 \mathrm{~mm})$ (parallel to the moving course) with a cover region of $(25 \mathrm{~mm} \times 25 \mathrm{~mm})$, that are welded in the focal point of the cover zone. Tables (1) and (2) show the mechanical properties of the materials used. The FSSW process procedure has been done in three stages: First stage, the pre- heating was achieved for each welded sample before the plunging step in order to generate the heat in samples, second stage, the tool pin was plunged from upper, third stage, the tool is removed easily. The FSSW procedure was accomplished utilizing a vertical all-inclusive processing machine to make the cover welded joints where the sheet of carbon steel was upper that set over the Aluminum sheet which was the lower sheet. In order to develop the FSSW process, a properly designed clamping fixtures of carbon steel plates were used to fix the work- pieces or metal sheets to be welded. Additionally, backing sheets are used to get the perfect joints of lap spot. The dimensions of the work piece are $(25 \mathrm{x} 25) \mathrm{mm}^{2}$ overlap area. Through FSSW, the frictional with the pin of shoulder and the workpiece creates the greater part of the warmth vitality for joining. The instrument utilized as a part of the welding forms are machined from fast apparatus steel that has hardness of $54 \mathrm{HRC}$. The tool has been designed from tungsten carbide (in this study had $10 \mathrm{~mm}$ diameter). A key geometrical feature of the tool is shown in Figure (2) which was held by a standard tool holder utilize to make the joints in this work.

Figure (3) illustrates the die assembly and Figure (4) show the welding spacemen. The welding parameters used to achieve the FSSW joints are listed in table (3). 


\section{ANSYS MODEL OF FSSW}

FSSW is the coupled problem (two degree of freedom: temperature and displacement coupled together in this process).i.e. when this field is analyzed contains two physical phenomena coupled together. Firstly, the model is generated by a pre-processor with the dimensions: Length $(\mathrm{L})=100 \mathrm{~mm}$ and Width $(\mathrm{W})=25 \mathrm{~mm}$, As indicated by American Welding Society (AWS) opposition welding handbook. The overlap spot joint alignment and dimensions are shown in Table (4) and Figure (5). The overlap joint sample has dimensions of $25 \mathrm{~mm}$ wide and $175 \mathrm{~mm}$ length. Due to symmetry meshing the model with SOLID226 with key opt (1)=11 is used to mesh the half model as shown in Figure(6). Two ways are used for solving coupled field problems, firstly solving the problem as a single field problem and applied it's result as an input load to the other field problem, typically named "one way coupling", or by solving two fields at the same time that can be used for thermal and structural degrees of freedom. In this study, one way coupling is used in which thermal analysis was conducted using transient thermal and then transient structure based on the result of the transient thermal analysis. This model was performed by using ANSYS15, then simulated to achieve the parametric study to observe the effect of pin's depth on the temperature distributions and stress distributions. Temperature dependent thermal properties of AA2024T3 Aluminum alloy and carbon steel (1006-AISI) were used in FE model. And the total frictional heat generated by friction torque under an axial load is

$Q=\frac{2}{3} \pi(1-\delta) \omega \mu P^{3}$

where:

$\mu=$ Coefficient of friction

$\mathrm{P}=$ Interfacial pressure

$\delta=$ Slip factor

$\omega=$ Angular speed of pin

Hence, the heat flux generated according to our data is illustrated in table(5).

The incremental theory of plasticity is utilized in the coupled field (temperature and displacement) analysis. The plastic mis-sharpening of the metals is expected to comply with the von Mises yield measure and the related stream run the show. Zhu and Chao relationship is used to consider the rate components between thermal stresses, $\sigma_{i j}$, and thermal strains, $\varepsilon_{i j}$, is described by assuming that the thermos coupled model follows the yield criterion. This model is assurance the occurrence of transient behavior between the stresses $\sigma_{i j}$ and the strain, which can be observed by:

$\dot{\varepsilon} \quad{ }_{i j}=\frac{1+v}{E} \dot{\sigma} \quad{ }_{i j}-\frac{v}{E} \dot{\sigma} \quad k k \delta_{i j}+\lambda s_{i j}+\left[\alpha+\frac{\partial \alpha}{\partial T}\left(T-T_{o}\right)\right] \dot{T}$

where $E, v$, and $\alpha$ are the modulus of elasticity, Poisson's ratio, and thermal expansion coefficient in $S_{i j}=\sigma_{i j}-\left(1 / 3 \sigma_{k k} \delta i j\right)$, respectively. This equation represents the deviatoric stresses components $\lambda, T_{o}$, and $(\cdot)$ denote the plastic flow factor, room temperature, and time differences. Strain rate $(\varepsilon)$ affects friction coefficient $(\mu)$. This phenomenon was reported in many studies, including that of Soundararajan et al. used a range of $\mu$. Other researchers have applied the values of $\mu$ is constant to evaluate the all effects of both thermal and plastic factors on the FSSW process. To determine the distributions of stresses and strains for the welded sheets, the results of the transient temperature analysis step, save as loading against displacement transient analysis step. The effects of temperature dependent material properties are utilized in the mechanical analysis, the isotropic Hooke's rule is used for the temperaturedependent Young's modulus. 


\section{RESULTS AND DISCUSSION}

Coupled field analysis is used when two or more physical phenomena coupled together, like a temperature distribution given an increased to thermal stresses and strains. Temperature distributions and thermal cycles results during friction stir welding the device rotates in work pieces without plunging. Friction is created in plunging and stirring phase, hence closed metal to the tool's device is warmed and softened. The softened upper and lower workpieces of A12024-T3 and Carbon steel respectively, mixed together in the stirring phase which caused the weld joint. Via FSSW process, high temperatures and thermal cycles in nugget are produced (weld) zone and base metals as shown in Figure(7). The nugget zone exposes to maximum or peak temperature due to rapid heating and cooling cycles via welding, where the temperature may be increased to re-crystallization temperature because recrystallization requires diffusion and diffusion takes time. Then the temperature decreases toward the TMAZ,HAZ and base metal which becomes the longer the material stays at large temperature, so that grain growth in HAZ and base metal, as shown in Figure(7). It was noticed that the maximum temperature was $242.57^{\circ} \mathrm{C}$ in the nugget region of dissimilar spot weld, at $15 \mathrm{sec}$ with depth of $0.4 \mathrm{~mm}$ and $135.752^{\circ} \mathrm{C}$ at $10 \mathrm{sec}$ with depth of $0.2 \mathrm{~mm}$, as in Figure(8).

\section{CONCLUSIONS}

From these results can conclude the following

1- The maximum temperature was $242.57^{\circ} \mathrm{C}$ in the nugget regionfor dissimilar spot weld, at $15 \mathrm{sec}$ with depth of $0.4 \mathrm{~mm}$ and $135.752^{\circ} \mathrm{C}$ at $10 \mathrm{sec}$ with depth of $0.2 \mathrm{~mm}$

2- The equivalent stress is directly proportional with time of welding. And the depth of the pin. 


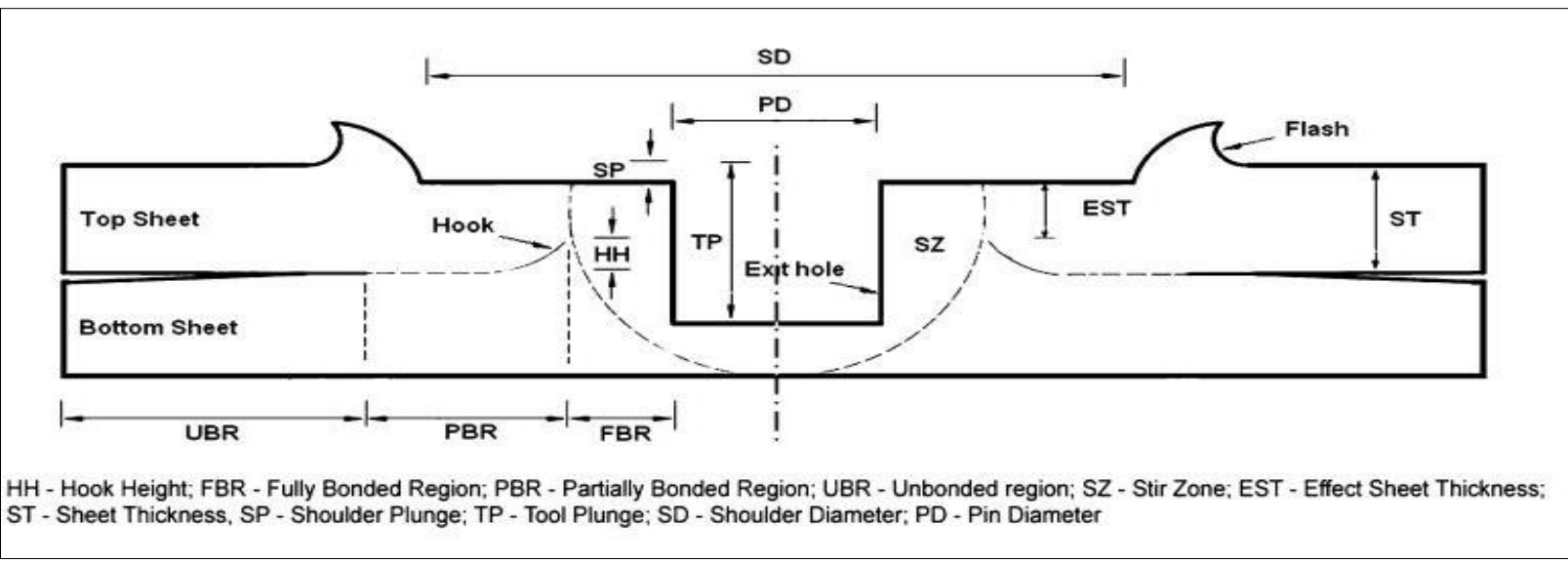

Fig.1 Schematic cross-sectional view of a FSSW [Badarinarayan, et.al]

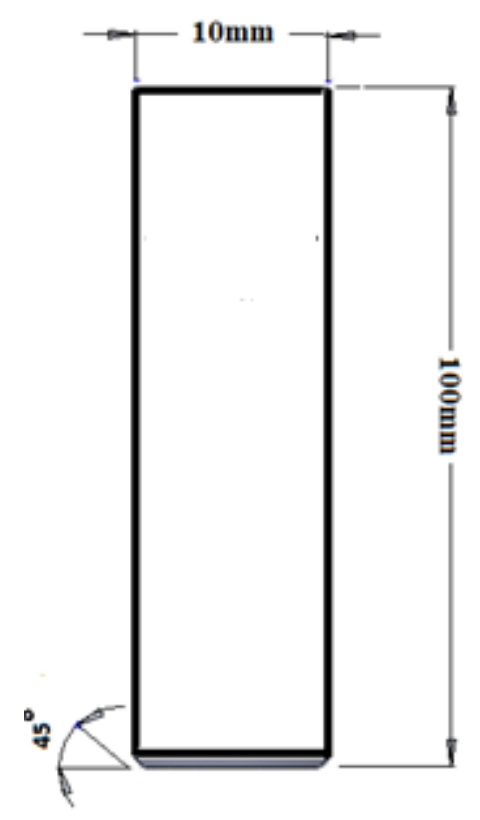

Fig.2 Tool geometrical dimension
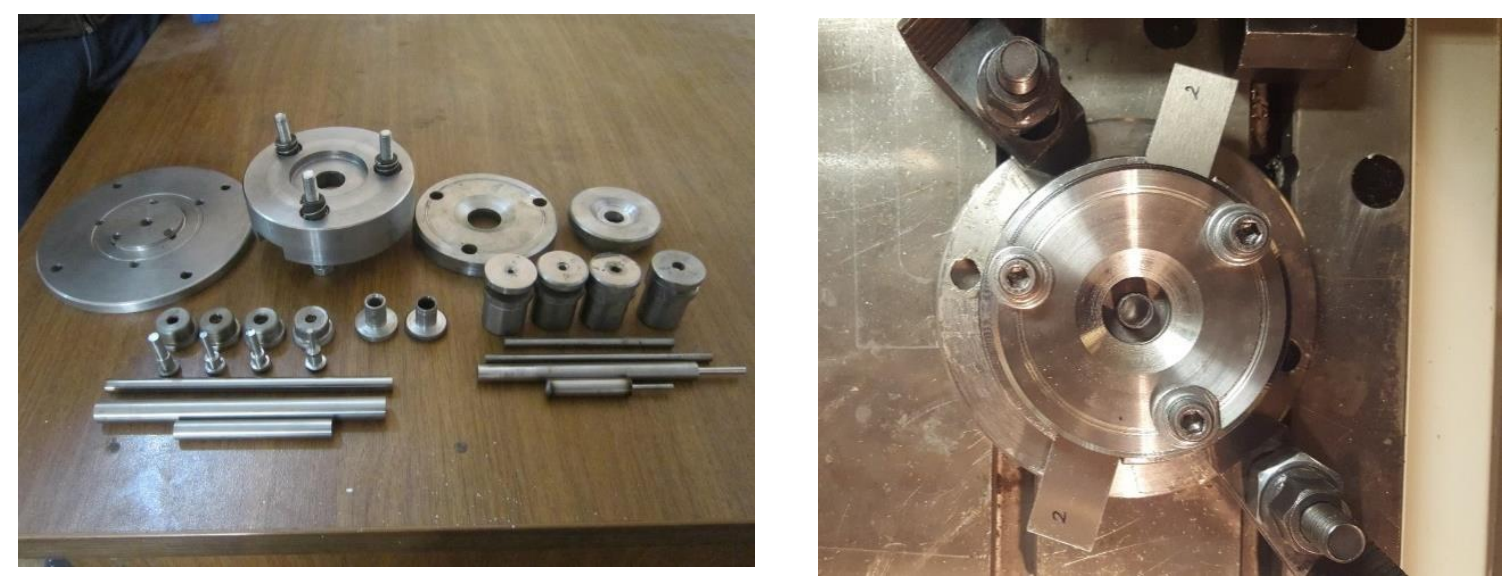

Fig.(3) Dies assembly 

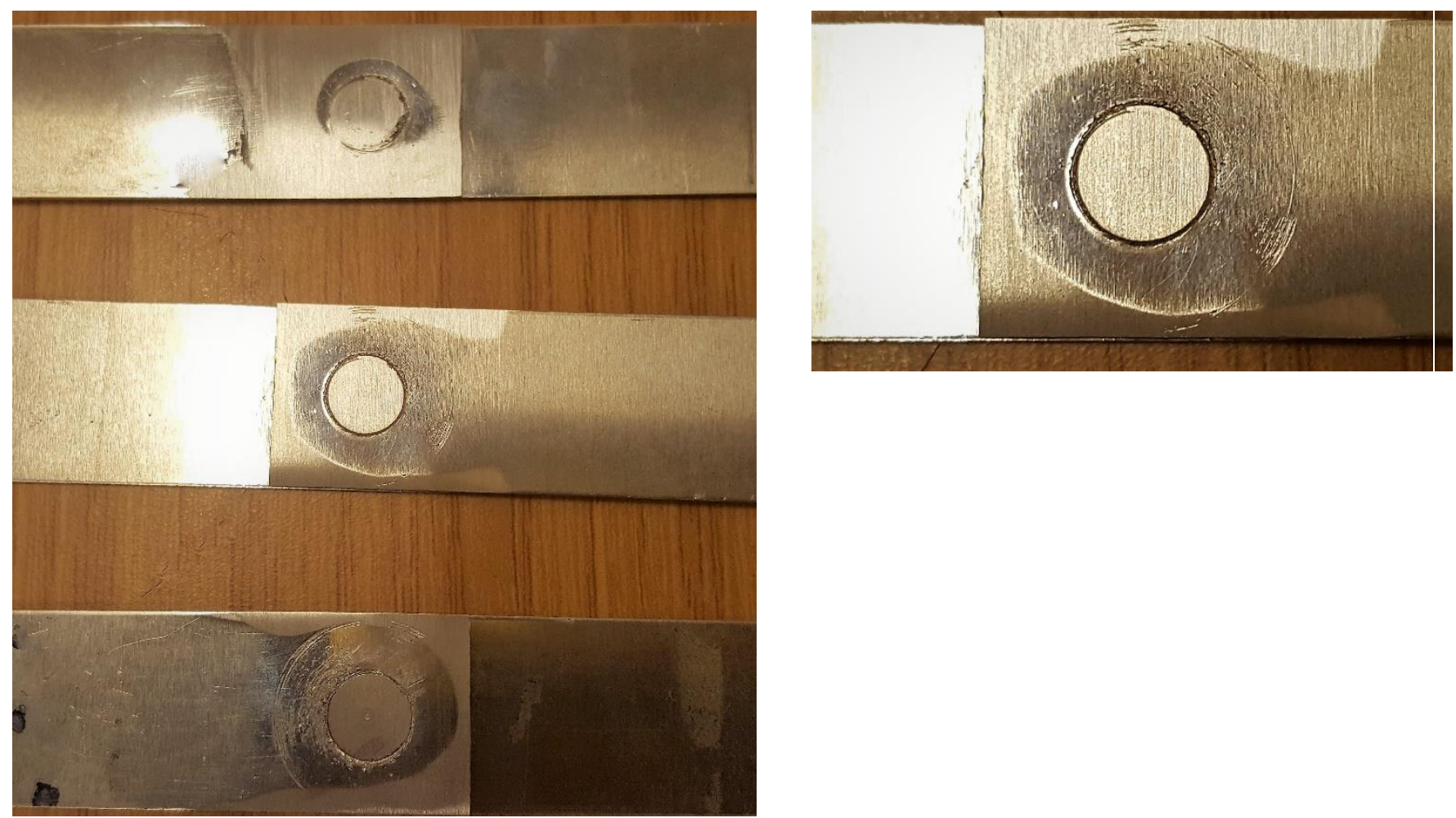

Fig.(4) Specimens for FSSW

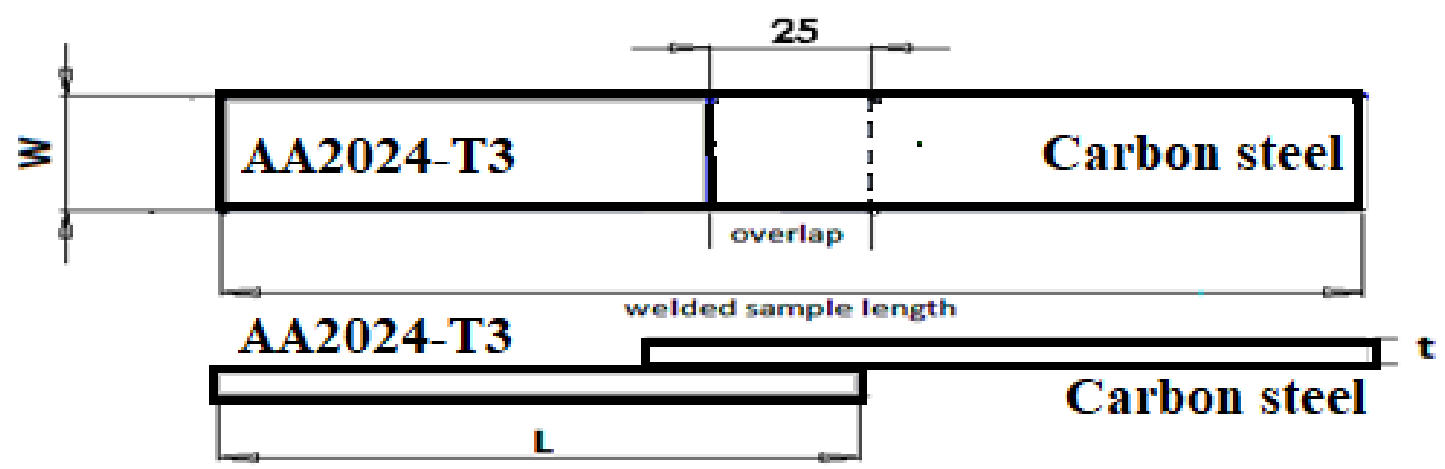




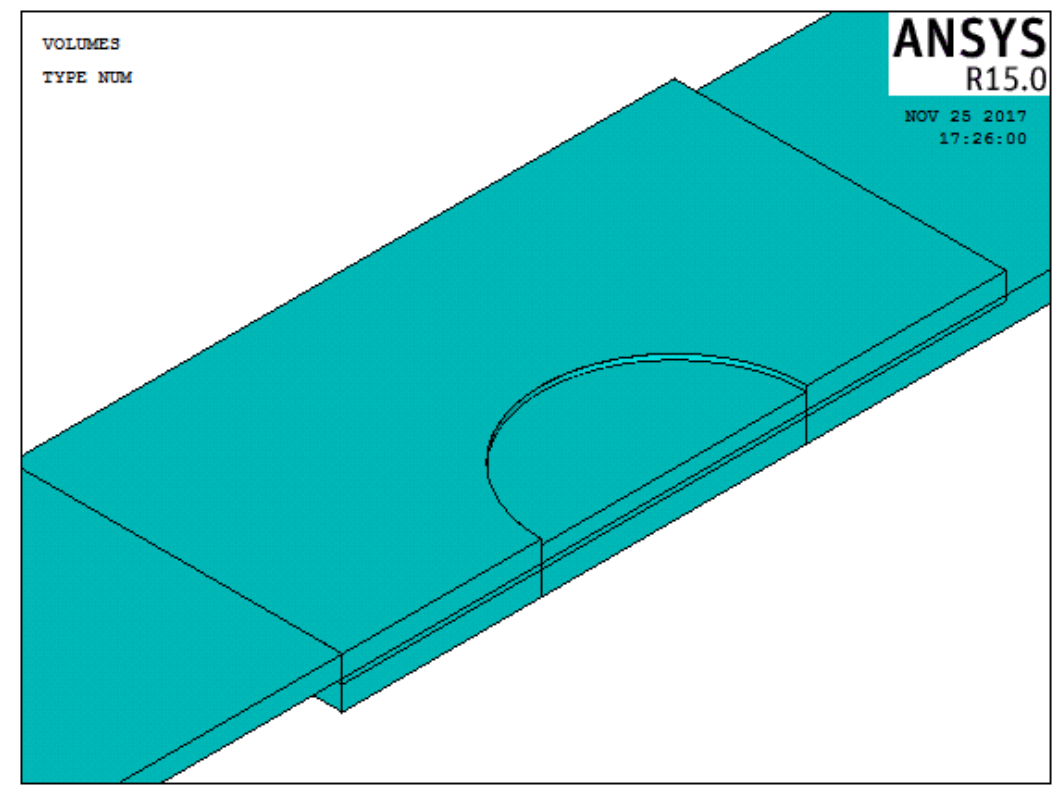

Fig.5 Overlapping of FSSW sample (All dimensions in mm).

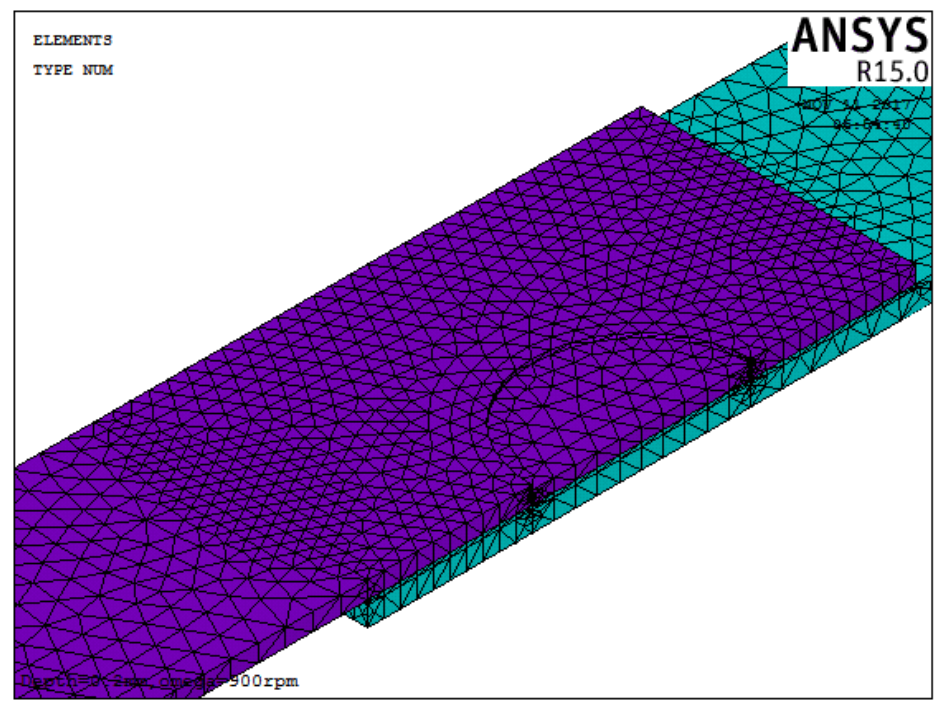

Fig.6 Meshing the FSSW model 


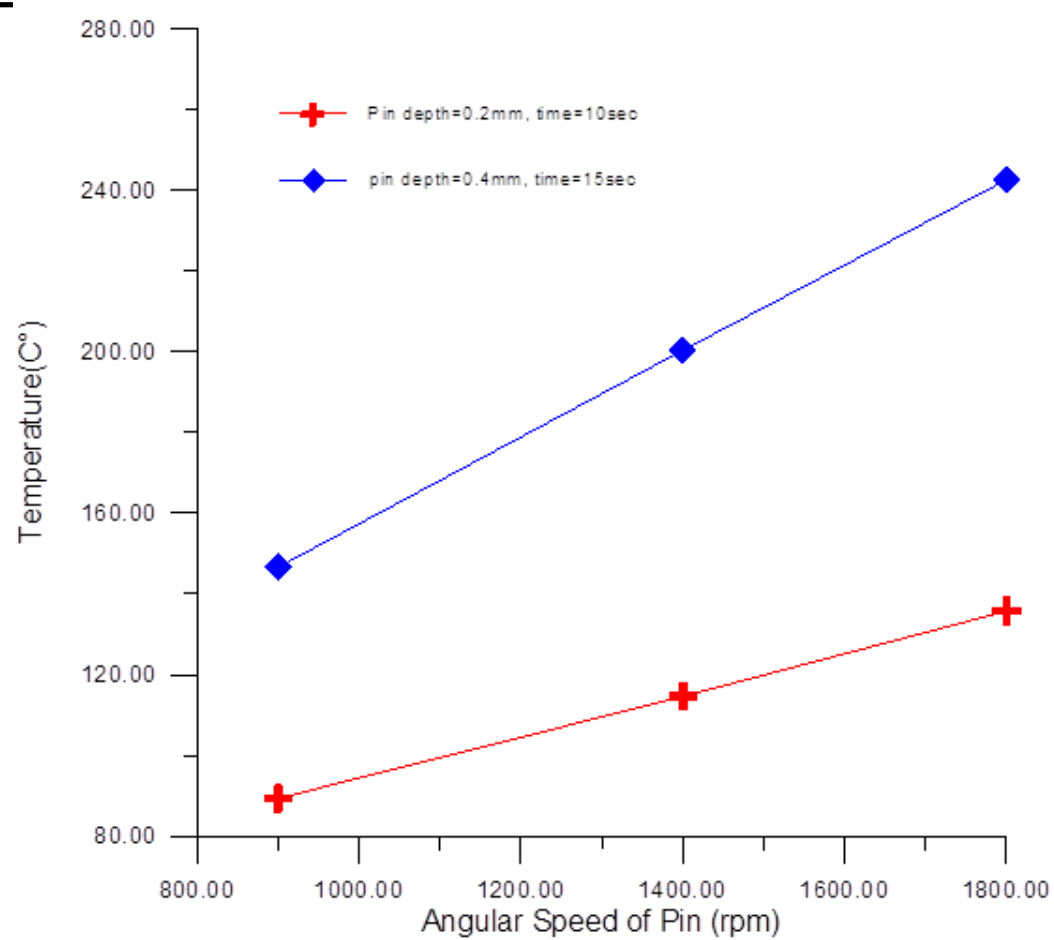

Fig.(7) Temperature vs angular speed of pin in FSSW

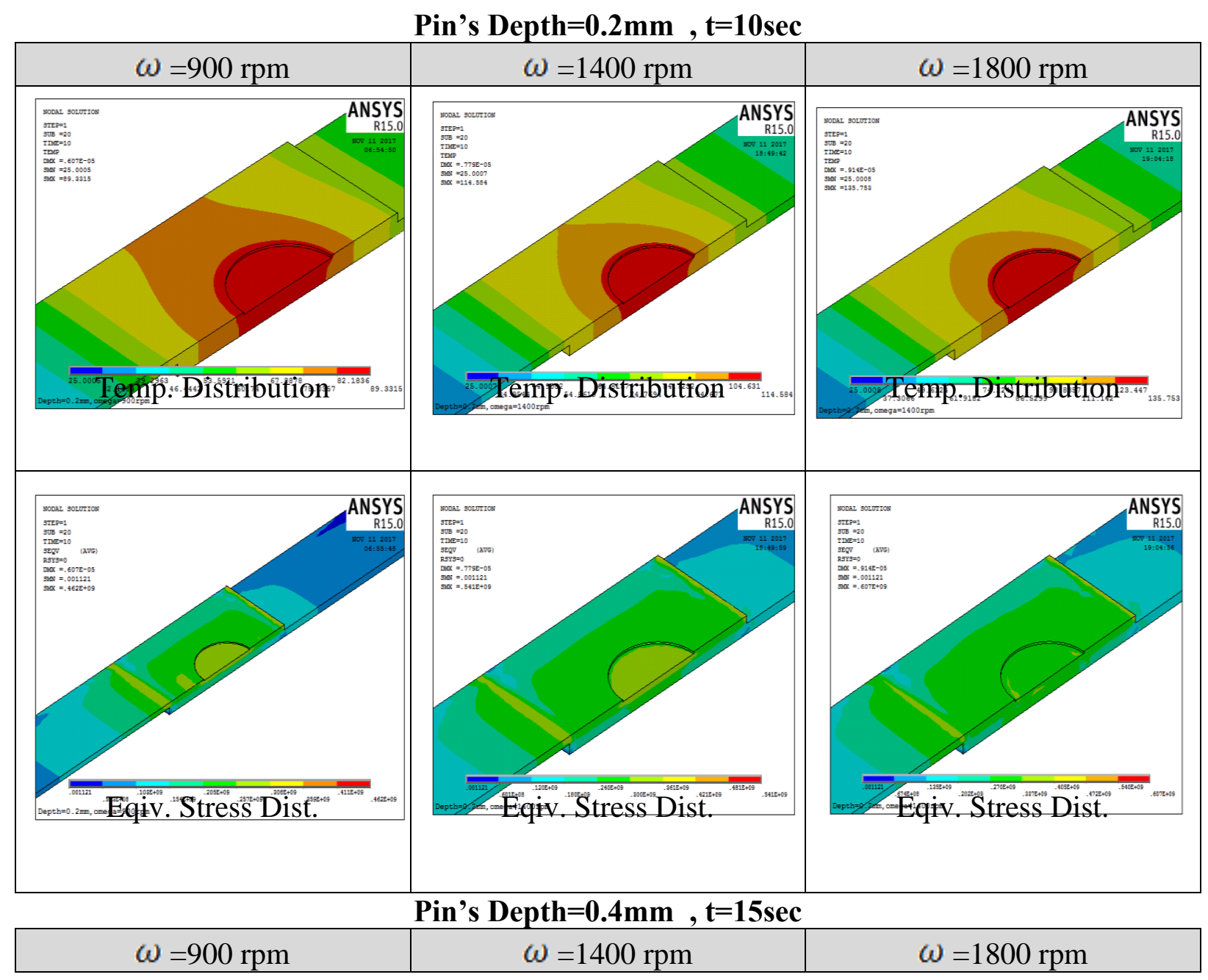




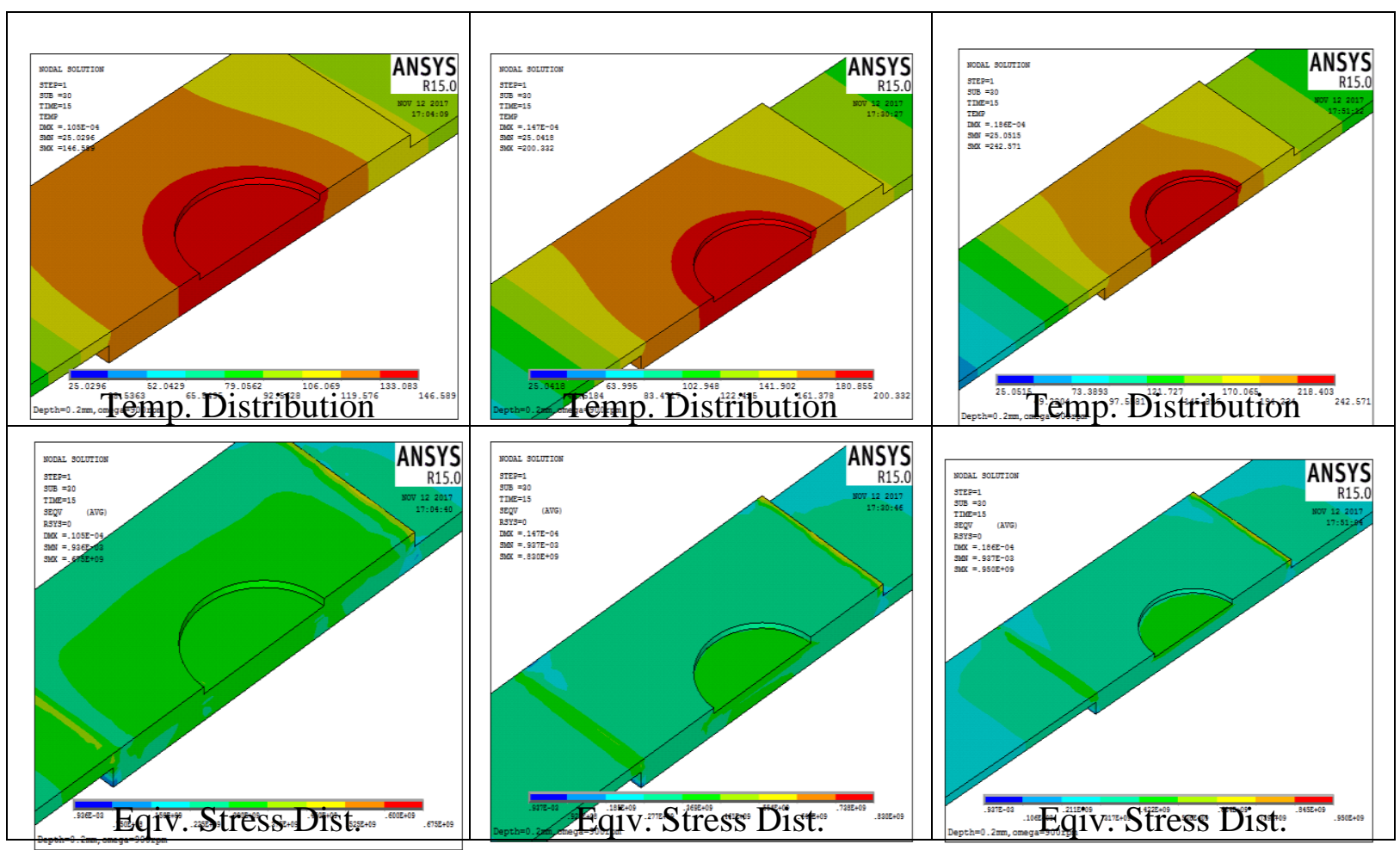

Fig. (8) The Temperature and stress distribution for different depth and time

Table 1: mechanical properties of AA2024-T3 aluminum alloy

\begin{tabular}{|c|c|c|}
\hline$\sigma_{\mathrm{u}}(\mathrm{MPa})$ & $\sigma_{\mathrm{y}}(\mathrm{MPa})$ & \% Elongation \\
\hline $454.7-463$ & $315.5-329.3$ & 19 \\
\hline
\end{tabular}

Table 2: mechanical properties of carbon steel (1006-AISI)

\begin{tabular}{|c|c|}
\hline$\sigma_{\mathrm{u}}(\mathrm{MPa})$ & $\sigma_{\mathrm{y}}(\mathrm{MPa})$ \\
\hline 229.12 & 127.7 \\
\hline
\end{tabular}

Table 3: FSSW parameters for the carbon Steel and AA2024-T3

\begin{tabular}{|c|c|c|c|}
\hline Rotation speed (rpm) & Feed rate $(\mathrm{mm} / \mathrm{min})$ & $\begin{array}{c}\text { Preheat (dwell time) } \\
(\mathrm{sec})\end{array}$ & $\begin{array}{c}\text { Depth } \\
(\mathrm{mm})\end{array}$ \\
\hline $1800,1400,900$ & 16 & 10,15 & $0.2,0.4$ \\
\hline
\end{tabular}

Table 4: Dimensions of welded samples

\begin{tabular}{|c|c|c|c|c|}
\hline Type of material & $\begin{array}{c}\text { Thickness }(\mathrm{t}) \\
\mathrm{mm}\end{array}$ & $\begin{array}{c}\text { Width (W) } \\
\mathrm{mm}\end{array}$ & $\begin{array}{c}\text { Length (L) } \\
\mathrm{mm}\end{array}$ & $\begin{array}{c}\text { Contact overlap } \\
\mathrm{mm}\end{array}$ \\
\hline $\begin{array}{c}\text { (AA2024-T3) Aluminum } \\
\text { alloy }\end{array}$ & 1.1 & $25 \mathrm{~mm}$ & $100 \mathrm{~mm}$ & $25 \mathrm{~mm}$ \\
\hline (10sfvzsteelt & 0.8 & $25 \mathrm{~mm}$ & $100 \mathrm{~mm}$ & $25 \mathrm{~mm}$ \\
\hline
\end{tabular}


Table 5 : Heat generated and heat flux generated in FSSW

\begin{tabular}{|c|c|c|c|}
\hline \multicolumn{4}{|c|}{ Pin's Depth=0.2mm } \\
\hline$\omega(\mathrm{rpm})$ & $\begin{array}{l}\mathrm{Q} \text { (watt) } \\
\text { Eq.(1) }\end{array}$ & $\begin{array}{l}\mathrm{q} \text { at tip of pin } \\
\left(\mathrm{watt} / \mathrm{m}^{2}\right)\end{array}$ & $\begin{array}{l}\text { Q at tip side } \\
\left(\text { watt } / \mathrm{m}^{2}\right)\end{array}$ \\
\hline 900 & 15.1 & 192356 & 980519.5 \\
\hline 1400 & 23.3 & 296815 & 1484076.5 \\
\hline 1800 & 30.17 & 384331 & 1921656 \\
\hline \multicolumn{4}{|c|}{ Pin's Depth $=0.4 \mathrm{~mm}$} \\
\hline$\omega(\mathrm{rpm})$ & $\begin{array}{l}\text { Q (watt) } \\
\text { Eq.(1) }\end{array}$ & $\begin{array}{l}\mathrm{q} \text { at tip of pin } \\
\left(\text { watt } / \mathrm{m}^{2}\right)\end{array}$ & $\begin{array}{l}\text { Q at tip side } \\
\left(\text { watt } / \mathrm{m}^{2}\right)\end{array}$ \\
\hline 900 & 20.92 & 266497 & 1332484 \\
\hline 1400 & 32.54 & 414522 & 2072611.5 \\
\hline 1800 & 41.83 & 532866 & 2664331 \\
\hline
\end{tabular}

\section{REFERENCES}

Badarinarayan H., Hunt F., Okamoto K., Friction Stir Spot welding, Friction Stir Welding and Processing, ASM International, Materials Park, Pages 235-272, 2007.

Figner G., Vallant R., Weinberger T., Schrottner H., Pasic H., Enzinger N. "Friction Stir Spot Welds between aluminium and steel automotive sheets: influence of welding parameters on mechanical properties and microstructure" Welding in the World, Vol. 53, 2009.

Bozzi S., Helbert-Etter A.L., Baudin T., Criqui B., Kerbiguet J.G. "Intermetallic compounds in Al 6016/IF-steel friction stir spot welds" Materials Science and Engineering A 527 (2010) 4505-4509.

Chen Y.C., Gholinia A., Prangnell P.B. "Interface structure and bonding in abrasion circle friction stir spot welding: A novel approach for rapid welding aluminium alloy to steel automotive sheet" Materials Chemistry and Physics 134 (2012) 459- 463.

Sun Y.F., Fujii H., Takaki N., Okitsu Y. "Microstructure and mechanical properties of dissimilar Al alloy/steel joints prepared by a flat spot friction stir welding technique" Materials and Design 47 (2013) 350-357.

D. Klobcar, J. Tusek, A. Skumavc, A. Smolej, " Parametric study of friction stir spot welding of aluminum alloy 5754 " ,ISSN 0543-5846 METABK 53(1), pp. 21-24 (2014).

Mukuna P. Mubiayi, IAENG and Esther T. Akinlabi, IAENG, “ Friction Stir Spot Welding of Dissimilar Materials: An Overview "Proceedings of the World Congress on Engineering and Computer Science 2014, Vol II, WCECS 2014, 22-24 October, 2014, San Francisco, USA.

MunaK.Abbass, Sabah Kh. Hussein, Ahmed Adnan Kudair, "Optimization of Friction Stir Spot Welding Parameters of Dissimilar Welded Joints of Aluminum Alloy (AA2024T3) with Pure Copper Sheets", International Journal of Engineering Sciences \& Research Technology ,4.(12): December, 2015. 
Timothy J M., 'Friction Stir Welding of Commercially available Superplastic Aluminium', Ph.D. thesis, Department of Engineering and Design, Brunel University, Brunel, 2008.

HarshaBadarinarayan, 'Fundamentals of friction stir spot welding', Ph.D. thesis, Missouri University of Science And Technology, UnitedState, 2009.

American Welding Society," Resistance Welding Theory and Use", Reinhold Publishing Corporation New York, Chapman \& Hall, LTD , London 1956.

Huebner H., Dewhirst D., Smith D. E., Byrom, T. , "The Finite Element Method for Engineers", $4^{\text {th }}$ ed., New York: J. Wiley. (2001).

Awang M., "Simulation of Friction Stir Spot Welding (FSSW) Process: Study of Friction Phenomena" Ph.D. thesis, Department of Mechanical and Aerospace Engineering, Morgantown, West Virginia, 2007.

Dr.Kareem N. Salloomi, Dr. Laith Abed Sabri, Yahya M. Hamad, SanaaNuman Mohammed , "3-Dimensional Nonlinear Finite Element Analysis of both Thermaland Mechanical Response of Friction Stir Welded 2024-T3Aluminum Plates" Journal of Information Engineering and Applications, Vol.3, No.9, 2013

Nadan R., Roy G.G., Lienert T.J., and Derbroy T. "Three dimensional heat and material flow during friction stir welding of mild steel”, Acta. Materialia, No.55, P.883-895, 2007.

Hani Aziz Ameen ,Ahmed HadiAbood, NabeelShallalThamer "Theoretical And Experimental Investigation Of Friction Stion Stir Welding For Copper Alloy" Al-Qadisiya Journal For Engineering Sciences ,Vol. 6, 2013.

X. K. Zhu and Y. J. Chao, "Numerical simulation of transienttemperature and residual stresses in friction stirwelding of 304Lstainless steel," Journal of Materials Processing Technology, Vol.146, No. 2, pp. 263-272, 2004.

J.L. PerezCastellanos and A. Rusinek, "Temperature increaseassociated with plastic deformation under dynamic compression:application to aluminum alloy AL 6082," Journal ofTheoretical and Applied Mechanics, Vol. 50, No. 2, pp. 377-398,2012.

V. Soundararajan, S. Zekovic, and R. Kovacevic, "Thermo-mechanicalmodel with adaptive boundary conditions for frictionstir welding of Al 6061," International Journal of Machine Toolsand Manufacture, Vol. 45, No. 14, pp. 1577-1587, 2005.

D. Trimble, J. Monaghan, and G. E. O'Donnell, "Force generationduring friction stir welding of AA2024-T3," CIRP Annals-Manufacturing Technology, Vol. 61, No. 1, pp. 9$12,2012$.

SindoKou , Welding Metallurgy ,2 ${ }^{\text {nd }}$ edition, John Wiley and Sons, Inc. Publication, 2003.

Sadiq Aziz Hussein, S. Thiru, R. Izamshah, and Abd Salam MdTahir, "Unstable Temperature Distribution in Friction Stir Welding", Advances in Materials Science and Engineering, Volume 2014 , 2014, Article ID 980636, 8pages , http://dx.doi.org/10.1155/2014/980636 